\title{
Numerical Simulation of the Effect of Dynamic Stress on the Rock Surrounding a Mine Roadway
}

\author{
Jun-hua Xue, Ke-liang Zhan $\mathbb{D}^{\mathrm{D}}$, Xuan-hong Du, and Qian Ma \\ School of Safety Science and Engineering, Xi'an University of Science and Technology, Xi'an, Shanxi 710054, China \\ Correspondence should be addressed to Ke-liang Zhan; 1265319567@qq.com
}

Received 1 November 2019; Revised 11 June 2020; Accepted 26 June 2020; Published 21 July 2020

Academic Editor: Hayri Baytan Ozmen

Copyright (C) 2020 Jun-hua Xue et al. This is an open access article distributed under the Creative Commons Attribution License, which permits unrestricted use, distribution, and reproduction in any medium, provided the original work is properly cited.

\begin{abstract}
In view of the damage of dynamic stress to the rock surrounding a mine roadway during coal mining, based on the actual geological conditions of Zhuji mine in Huainan, China, a UDEC model was established to study the influences of the thickness and strength of the direct roof above the coal seam and the anchorage effect on the stability of the roadway. The failure mechanism and effect of the dynamic stress on the rock surrounding a mine roadway were revealed. Under dynamic stress, cracks appear near the side of the roadway where the stress is concentrated. These cracks rapidly expand to the two sides of coal and rock mass. At the same time, the coal and rock mass at the top of the roadway fall, and finally, the two sides of coal and rock mass were broken and ejected into the roadway, causing a rock burst. However, when the same dynamic stress is applied to the roadway after supports are installed, there is no large-deformation failure in the roadway, which shows that, under certain conditions, rock bolting can improve the stability and seismic resistance of the surrounding coal and rock mass. Furthermore, by simulating the failure of surrounding rock with different strengths and thicknesses in the immediate roof, it is found that the thinner the roof, the greater the influence of the dynamic stress on the roadway; the stronger the roof is, the more likely the rock burst will occur with greater intensity under the same dynamic stress. A numerical simulation method was used to analyze the factors influencing rock bursting. The results provide a theoretical basis for research into the causes and prevention of rock bursts in deep mining areas.
\end{abstract}

\section{Introduction}

As mining depths increase in China, coal mining is becoming more complex. With the gradual increases in mining depth, the possibility of rock bursts increases [1-3]. As a typical dynamic disaster in a coal mine, a rock burst poses a significant threat to the efficient production of the coal mine and the safety of personnel. Therefore, it is necessary to predict and prevent rock bursts while mining [4-7]. Many scholars have investigated the mechanism of rock bursting, monitoring and early warning technology, and prevention and control technology. Tang [8-10] found that how the coal rock mass structure develops from stable equilibrium state to unstable equilibrium state is the research focus of rock burst. Kang et al. [11] used the self-developed explosion-proof seismic positioning monitoring system to monitor the fracture of coal strata in the process of advancing the face in Huafeng coal mine in Shandong Province. Through the analysis of the monitoring results, the main causes of rock burst were obtained. Bai et al. [12] developed an anchor cable with a negative Poisson's ratio effect. Through laboratory and field testing, the mechanical properties of a constant stiffness, large-deformation anchor cable were verified to be better than those of an ordinary anchor cable. Bai et al. [13] used coal and rock mass in mechanical tests to establish an expansion model of coal and rock to assess the influence of the expansion of surrounding rock on the rock burst. Tang [14] analyzed the No. 3213 working face in Xinjing coal mine by theoretical analysis and numerical simulation to study the influence of the roof slate layer on the rock burst in the deep large-height working face and provided valuable experience assisting the safe mining of other similar mines. Tan et al. [15] established the theoretical model of ultralow friction effect of a blocky rock mass considering the overburden pressure. Through the analysis, it is found that the change of normal force between blocks is the precondition for an 
ultralow friction effect, and the horizontal disturbance is the direct cause of horizontal displacement of working block. Liu et al. [16] reduced the constraint effect of roof and floor on coal seam by design of a displacement-control clamping test. The research results show that roof and floor can promote the formation of rock burst by locking the coal seam and the deformation of the coal seam itself. Jiang et al. [17] conducted a series of experiments on the screw steel bolt, studying the impact disturbance resistance of equal strength and unequal strength screw steel bolts under static load and impact load. He et al. [18] studied the mechanism of rock bursting in a hard roof by theoretical analysis and in situ assessment. It was found that the precursory information pertaining to rock bursts in a hard roof has two key characteristics: energy increase and a change in stress. Many scholars have discussed and summarized the theoretical development, monitoring technology, prevention technology, and problems faced with mine rock burst hazard and proposed research to improve the level of coal mine rock burst prevention $[19,20]$.

Although scholars have made achievements in the study of mechanism, monitoring methods, and crisis response measures of rock burst, there are many influencing factors of rock burst. In this paper, numerical simulation method was used to simulate and analyze the effects of bolt reinforcement, direct roof thickness, direct roof strength, and other factors affecting dynamic stress transmission and the stability of rock surrounding a mine roadway, so as to provide a reference for the prediction and prevention of rock bursts.

\section{Numerical Simulation Scheme and Model Establishment}

2.1. Numerical Simulation Scheme. According to data from the first mining face (No. 1111 (1)), Zhuji mine, Huainan, China, the influences of the thickness, strength of the direct roof above the coal seam, and the anchoring effect of the bolt on the stability of the roadway were simulated and analyzed. The specific calculation scheme is as follows:

(1) Under the conditions of original and applied vibration waves, we analyzed the influence of bolt reinforcement on the stability of the roadway

(2) The influence of direct roof thickness on the stability of a roadway was investigated

(3) The influence of direct roof strength on the stability of a roadway was analyzed

2.2. Numerical Model. The first mining face (No. 1111 (1)) in Zhuji mine, Huainan, has a surface elevation of $20 \mathrm{~m}$ and a working face elevation of -913.1 to $-879.7 \mathrm{~m}$, with a strike length of $1608 \mathrm{~m}$ and an inclination length of $220 \mathrm{~m}$. The dip angle is 1 to $5^{\circ}$, with an average dip of $3^{\circ}$. The thickness of the No. 11-2 coal seam on this surface is 0.1 to $2.1 \mathrm{~m}$, with an average thickness of $1.2 \mathrm{~m}$. The roof and floor are mudstone, with an average thickness of $9.9 \mathrm{~m}$; the old roof is fine sandstone and siltstone with an average thickness of $3.2 \mathrm{~m}$. The bottom is mudstone, with an average thickness of $4.5 \mathrm{~m}$.
The average thickness of the overlying coal is $4.2 \mathrm{~m}$, and the distance from the $11-2$ coal seam is $66 \mathrm{~m}$ (50 times the mining height). The bottom is formed in silty and fine sandstone, with local sandy mudstone. The field measurement of in situ stress shows that the range of vertical in situ stress is 19.3 to $20.6 \mathrm{MPa}$, the minimum horizontal principal stress is similar to the vertical principal stress, the lateral pressure coefficient is 1.32 to 1.38 , and the maximum principal stress acts in the east-west direction.

The numerical model was established according to the actual geological conditions. UDEC model size (length $\times$ height): $60 \mathrm{~m} \times 40.2 \mathrm{~m}$, and the roadway is horseshoe-shaped measuring $4 \mathrm{~m} 4 \mathrm{~m}$, with an upper arch radius of $2 \mathrm{~m}$, and the mechanical parameters of surrounding rock are as listed in Table 1.

Figure 1 shows the mechanical model of anchorage reinforcement; among them, a total of 11 bolts were installed in the roadway, five bolts were installed in the semicircular arc area above the roadway, and three bolts were installed on the left- and right-hand sides, respectively. The length of the bolts was $2.4 \mathrm{~m}$, the cross-sectional area was $314 \times 10-6 \mathrm{~m}^{2}$, and the pretightening force was $40 \mathrm{kN}$.

Boundary conditions of the static load model are as follows: the left and right horizontal hinge support constraints are adopted, and the bottom is fixed. The upper boundary is free and bears distributed load $q=R h$ exerted by the overburden, where $R$ is the average unit weight of the overburden $\left(25 \mathrm{kN} / \mathrm{m}^{3}\right)$; $h$ is the height of the overburden $(900 \mathrm{~m})$ according to the actual location to the No. 1111 (1) working face. In the dynamic calculation model, to reduce the influence of boundary reflection wave under the action of dynamic load, the boundary is set as a viscous boundary to simulate the boundary at infinity. The applied vibration wave is a cosine wave with a peak value of $20 \mathrm{MPa}$ and a frequency of $10 \mathrm{~Hz}$, specifically $y=20 \times 10^{6} \cos (2 \pi \cdot 10 t)$. The dynamic stress is applied between 20 and $40 \mathrm{~m}$ along the upper boundary of the model. At the same time, five monitoring points are set on the left- and right-hand sides of the roadway, mainly monitoring displacements in the $Y$ - and $X$-direction, of which the left five monitoring points are marked as $\mathrm{A}$ $(27.5,14.7), \mathrm{B}(27.5,15.1), \mathrm{C}(27.5,15.5), \mathrm{D}(27.5,15.9)$ and $E(27.5,16.3)$; and those on the right as $1(32.5,14.7)$, $2(32.5,15.1), 3(32.5,15.1), 4(32.5,15.9)$, and 5 (32.5, 16.3).

Under the action of dynamic load, the natural attenuation of motion and energy of geotechnical material exhibits hysteresis, which is related to frequency and other parameters. In fact, dynamic load is formed by the superposition of different frequency disturbances. In addition to the influences of different loading methods and loading paths, a damping function should be introduced to achieve the consistency with the real situation. The damping function is of the Rayleigh mass damping only type provided by UDEC, and the critical damping ratio is determined to be 0.1 through calculation.

The block diagram of the model under the original condition is shown in Figure 2. 
TABLE 1: Mechanical parameters of surrounding rock.

\begin{tabular}{lccccccc}
\hline $\begin{array}{l}\text { Rock } \\
\text { formation }\end{array}$ & $\begin{array}{c}\text { Thickness } \\
(\mathrm{m})\end{array}$ & $\begin{array}{c}\text { Density } \\
\left(\mathrm{kg} \cdot \mathrm{m}^{-3}\right)\end{array}$ & $\begin{array}{c}\text { Bulk modulus } \\
(\mathrm{GPa})\end{array}$ & $\begin{array}{c}\text { Shear modulus } \\
(\mathrm{GPa})\end{array}$ & $\begin{array}{c}\text { Cohesion } \\
(\mathrm{MPa})\end{array}$ & $\begin{array}{c}\text { Friction angle } \\
\left({ }^{\circ}\right)\end{array}$ & $\begin{array}{c}\text { Tensile strength } \\
(\mathrm{MPa})\end{array}$ \\
\hline $\begin{array}{l}\text { Spotted } \\
\text { mudstone }\end{array}$ & 11.5 & 2640 & 8 & 4.8 & 2.3 & 35 & 5 \\
Fine/siltstone & 3.2 & 2700 & 12 & 8.1 & 4.0 & 37 & 7 \\
Mudstone & 10 & 2640 & 8 & 4.8 & 2.3 & 35 & 28 \\
$11-2$ coal & 1.2 & 1300 & 8.5 & 8 & 4.8 & 2.3 & 35 \\
Mudstone & 4.5 & 2640 & 8.5 & 4 & 0.5 & 28 & 5 \\
$11-1$ coal & 0.8 & 1300 & 8 & 4.8 & 2.3 & 35 & 2 \\
Mudstone & 9 & 2640 & & & & & 5 \\
\hline
\end{tabular}

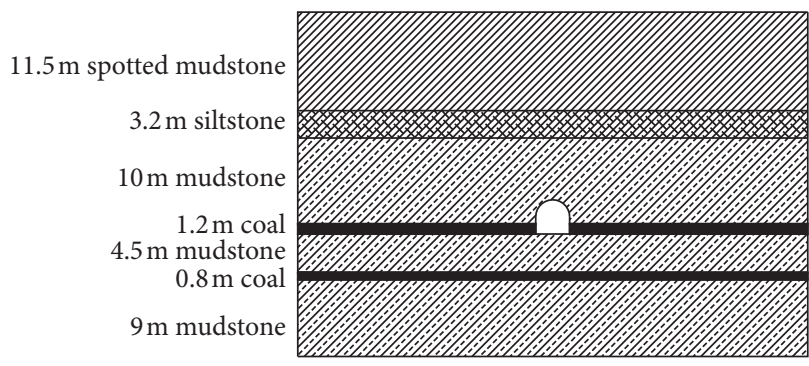

(a)

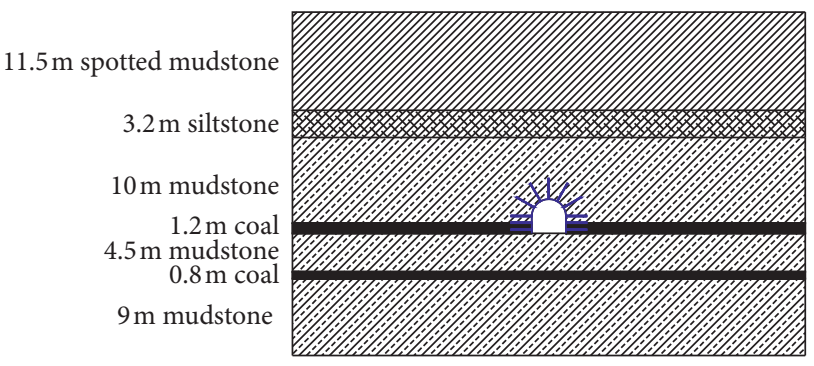

(b)

Figure 1: Mechanical model.

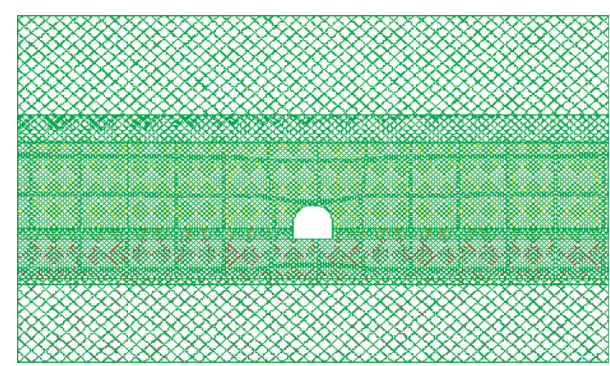

FIGURE 2: Schematic diagram of the model under original conditions.

\section{Analysis of Numerical Computation Results}

\subsection{Process of Rock Bursting under Original Conditions.} Under the original conditions, when the roadway depth was $900 \mathrm{~m}$ and the dynamic stress pulse had an amplitude of $20 \mathrm{MPa}$, the simulated results are as shown in Figure 3:

The whole process of rock burst induced by dynamic stress disturbance in rock surrounding a mine roadway is reproduced in Figure 3: the crack starts near the roadway side where the stress is concentrated and is about $2 \mathrm{~m}$ away from the roadway side boundary. With the disturbance caused by the stress wave, the crack rapidly expands from the starting position to the coal rock mass, mainly forming two cracks, which are symmetrically distributed on the left- and right-hand sides of the roadway, At the same time, affected by the vibration, the coal and rock mass in the top area of the roadway fell, and finally the two sides of the rock broke into pieces, which were thrown into the roadway, resulting in a rock burst.
Due to the left-right symmetry of the roadway and the vibration wave being applied symmetrically at the upper boundary, the overall deformation of the roadway is quasisymmetrical. To explore the location of coal body ejection when a rock burst occurs, Figure 4 can be obtained by sorting and analyzing data from the five monitoring points on the right-hand side:

As seen from Figure 4, the $x$ - and $y$-displacements of monitoring points 1 and 5 are similar. The displacement of monitoring point 2 is greater than that of monitoring points 1 and 5 , and the $x$ - and $y$-displacements of monitoring points 3 and 4 are greater than that of monitoring points 1,2 , and 5 , reaching a maximum value of about $0.8 \mathrm{~m}$. Therefore, it can be concluded that when the coal seam thickness is $1.2 \mathrm{~m}$, the coal and rock mass are mainly ejected from the boundary between the coal seam and the overlying strata.

3.2. Influence of Vibration Wave on Roadway under Anchored Conditions. After installing anchor bolts at the top and two sides of the roadway, a certain pretension was applied. When the roadway depth is $900 \mathrm{~m}$ and the dynamic stress amplitude is $20 \mathrm{MPa}$, the simulated results are as shown in Figure 5.

In Figure 5, the red line represents the shear force on the bolt, the blue line represents the displacement of the bolt in the $x$-direction, and the yellow line represents the displacement in the $y$-direction. Moreover, the maximum values of the shear force and the displacement in the $y$-direction of the bolt in different vibration periods are shown in Figures 6 and 7.

The use of anchor bolts can strengthen the stability of surrounding coal and rock mass and improve its ability to resist vibration to a certain extent. At the same time, through the analysis of shear stress and $y$-direction displacement of 


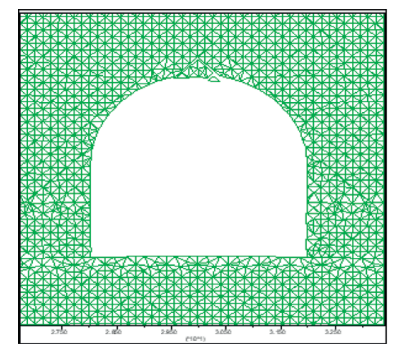

$0.03 \mathrm{~s}$

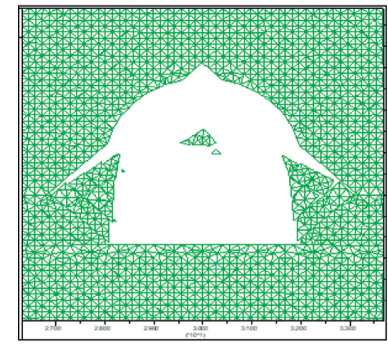

$0.5 \mathrm{~s}$

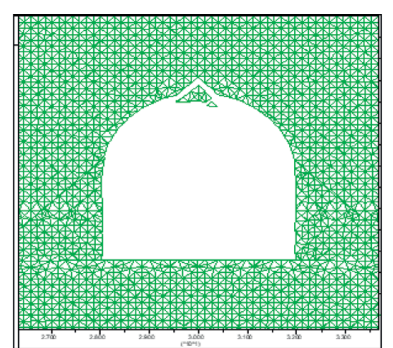

$0.1 \mathrm{~s}$

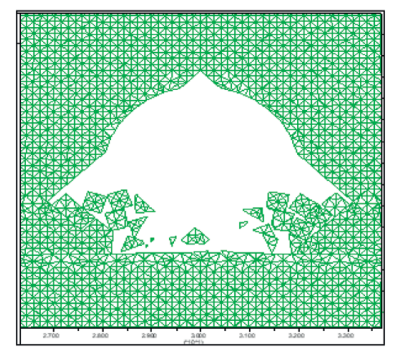

$1.0 \mathrm{~s}$

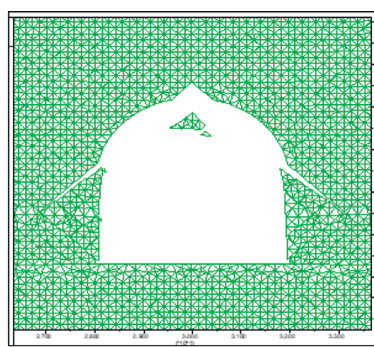

$0.3 \mathrm{~s}$

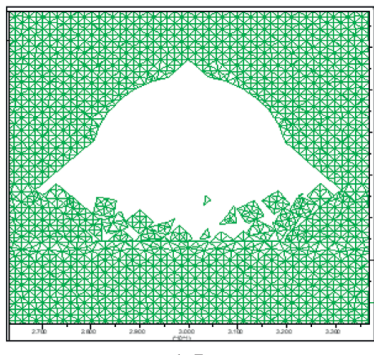

$1.5 \mathrm{~s}$

FIGURE 3: Impact pressure generation process under original conditions.

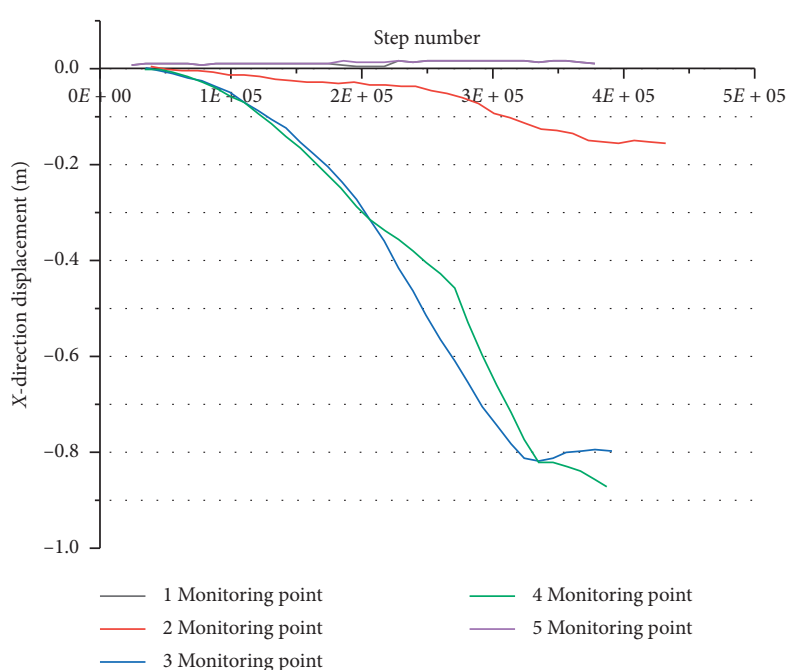

(a)

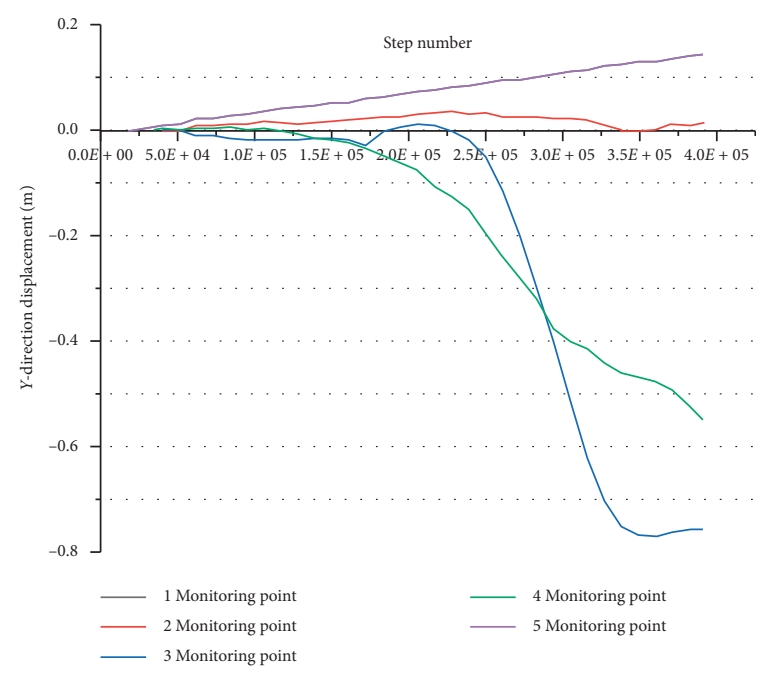

(b)

Figure 4: Comparison of different deformations on the right-hand side. (a) X-direction displacement. (b) $Y$-direction displacement.

different bolts, the shear stress on bolts on the upper semicircular arc of the roadway is relatively small in this horseshoeshaped roadway, especially in an arc of $30^{\circ}$ on each side of the central part, and the shear stress of bolts exhibits bilateral symmetry. By comparing the displacements in the $Y$-direction of each bolt at different times, the displacements in the $Y$ direction of bilateral symmetric bolts are similar.

\subsection{Influence of Direct Roof Thickness on the Roadway.} When the direct roof thickness is $2 \mathrm{~m}, 6 \mathrm{~m}$, and $10 \mathrm{~m}$, respectively, the influence of the direct roof thickness on the propagation characteristics of the vibration wave is investigated by studying the damage suffered by the roadway of different thicknesses. When the direct roof thickness is $2 \mathrm{~m}, 6 \mathrm{~m}$, and $10 \mathrm{~m}$, the failure of the roadway is as shown in Figures 8-10.

From Figures $8-10$, when the direct roof thickness is $2 \mathrm{~m}$, $6 \mathrm{~m}$, and $10 \mathrm{~m}$ respectively, the failure mode of the roadway is similar. The cracks start near the roadway side where the stress is concentrated and are about $2 \mathrm{~m}$ away from the roadway side boundary. With the disturbance of the dynamic stress, the cracks rapidly expand from the starting position to the coal and rock mass, mainly forming two cracks, which are symmetrically distributed on the left- and right-hand sides of the roadway and are subject to vibration at the same time. Under the influence of the stress wave, the coal and rock mass at the top of the roadway fall, and finally the two sides of the rock mass form fragments, which are thrown into the roadway, causing a rock burst. 


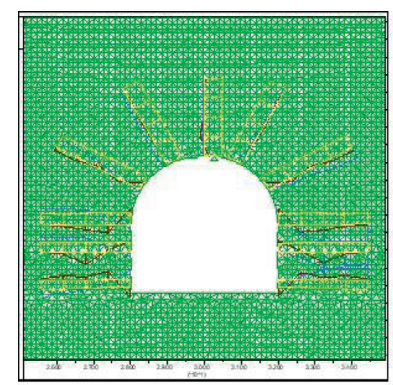

$0.03 \mathrm{~s}$
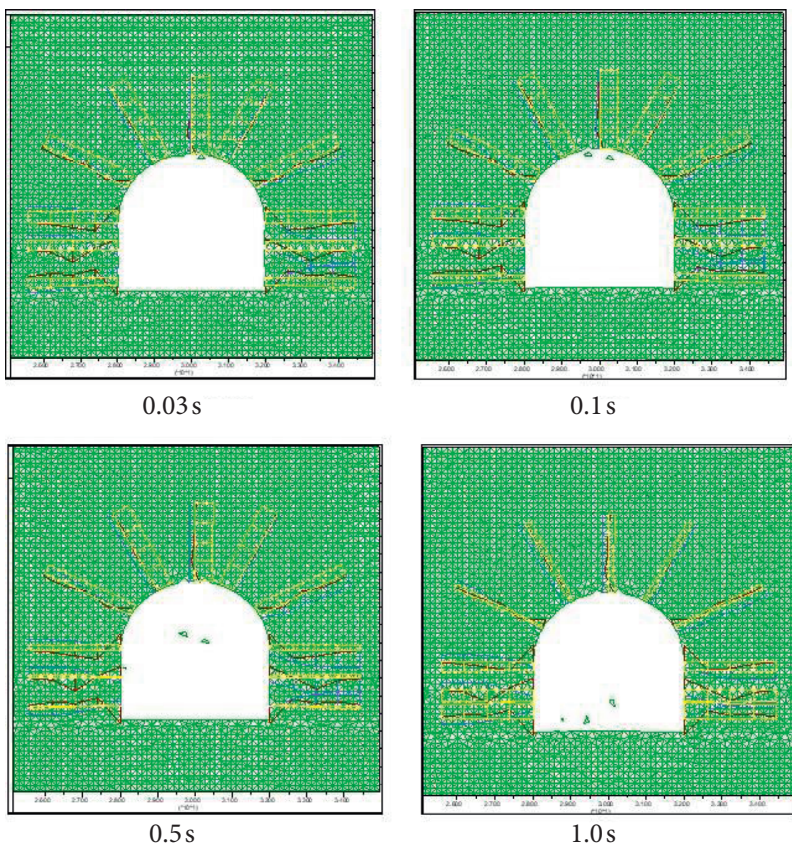

$0.1 \mathrm{~s}$
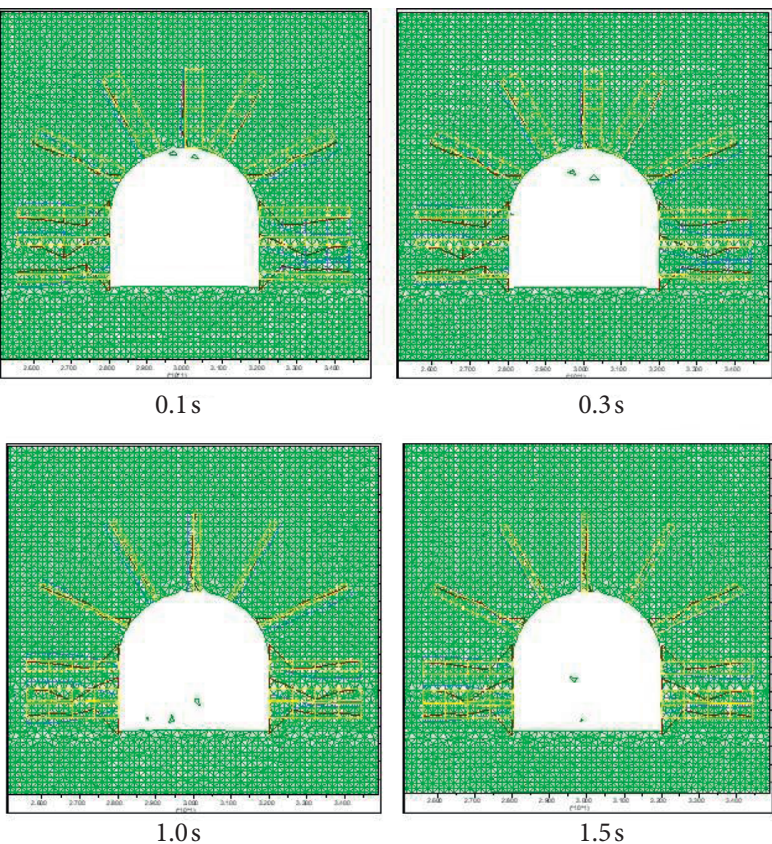

Figure 5: No impact pressure occurs in the anchored state.

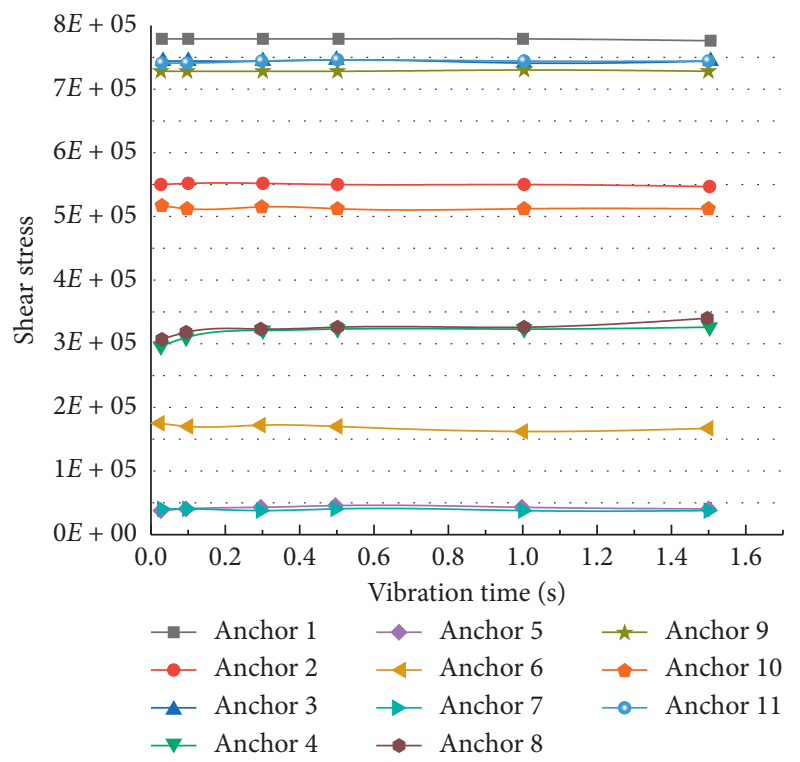

FIgURE 6: Shear stress distribution diagram of each anchor at different times.

Meanwhile, to explore the influences of different direct roof thicknesses on the roadway under the same conditions of roadway depth and vibration input, the deformations of the roadway at $\mathrm{t}=0.3 \mathrm{~s}$ and $0.5 \mathrm{~s}$ were compared (Figure 11).

Through the comparison of the deformations of the roadway at $0.3 \mathrm{~s}$ and $0.5 \mathrm{~s}$ with different direct roof thicknesses, the thinner the roof, the greater the deformation of the roadway. From the coal seam histogram of the working face, there is a layer of mudstone about $10 \mathrm{~m}$ above the coal seam and a layer of fine sandstone of $3.2 \mathrm{~m}$ thickness above the mudstone. When the roof is thinner, the corresponding

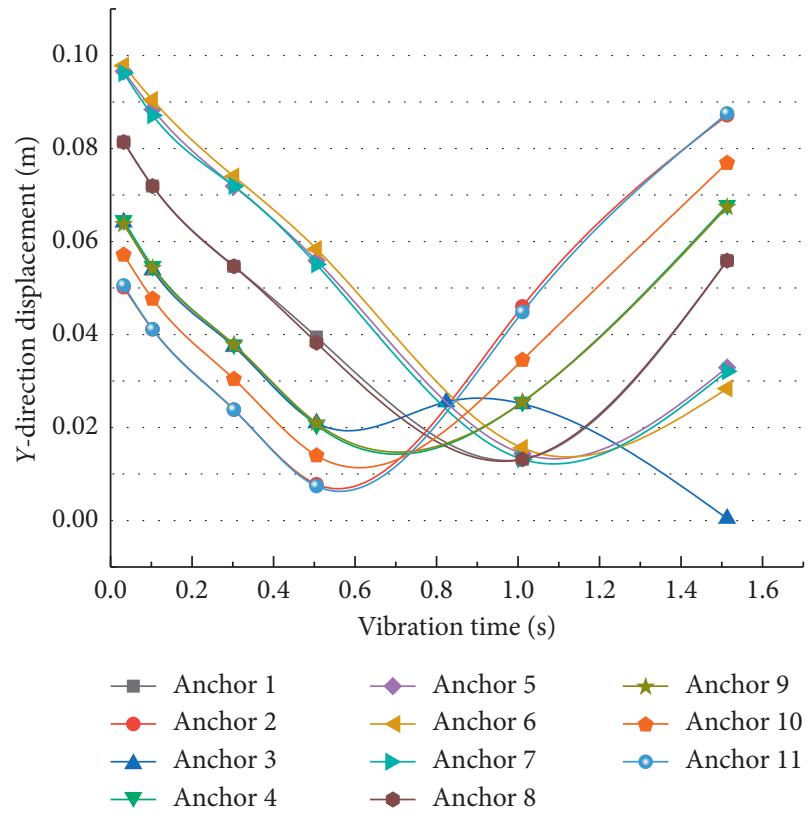

FIGURE 7: Displacement map of $y$-direction displacement of anchors at different times.

fine sandstone is thicker; because the mechanical parameters of the fine sandstone are greater than those of the mudstone, the attenuation coefficient of the vibration wave is smaller under the same level of fracture development. Therefore, when the same vibration wave is applied under the same conditions and the roof is thin, the deformation of the roadway increases.

According to the above analysis, under the specific rock structure of the working face, the thinner the roof, the lower the vibration wave attenuation, and the greater 

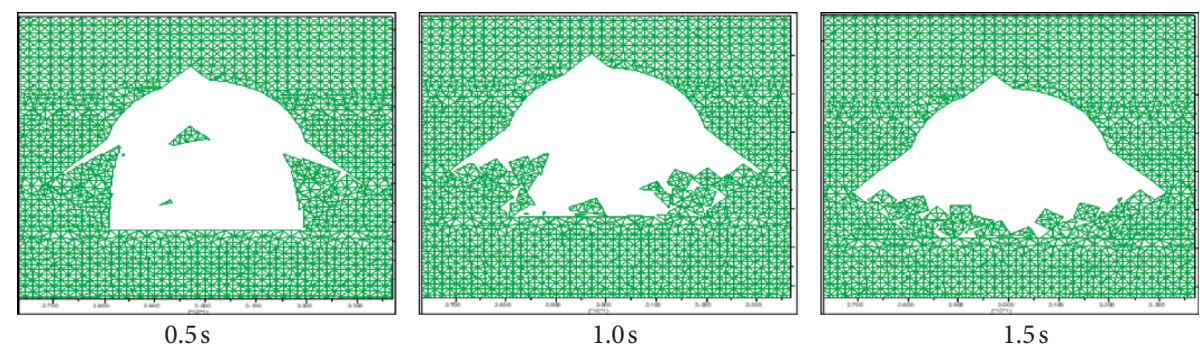

Figure 8: Roadway failure process under a $2 \mathrm{~m}$ thick roof.
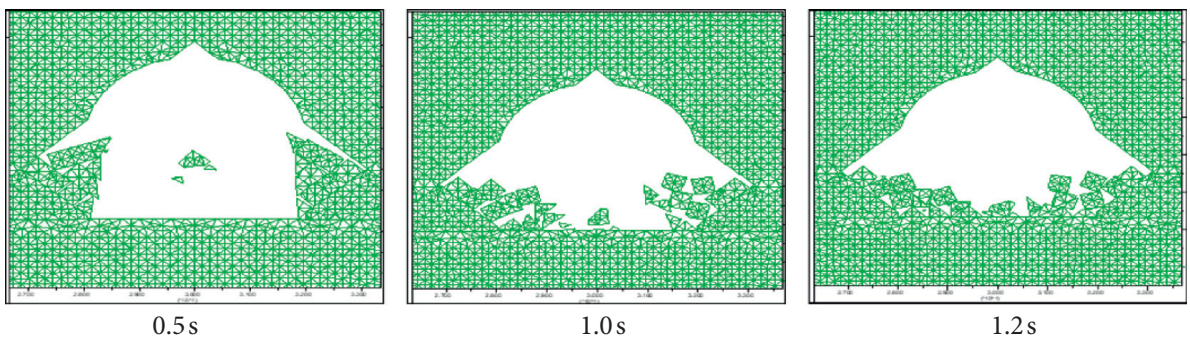

Figure 9: Roadway failure process under a $6 \mathrm{~m}$ thick roof.
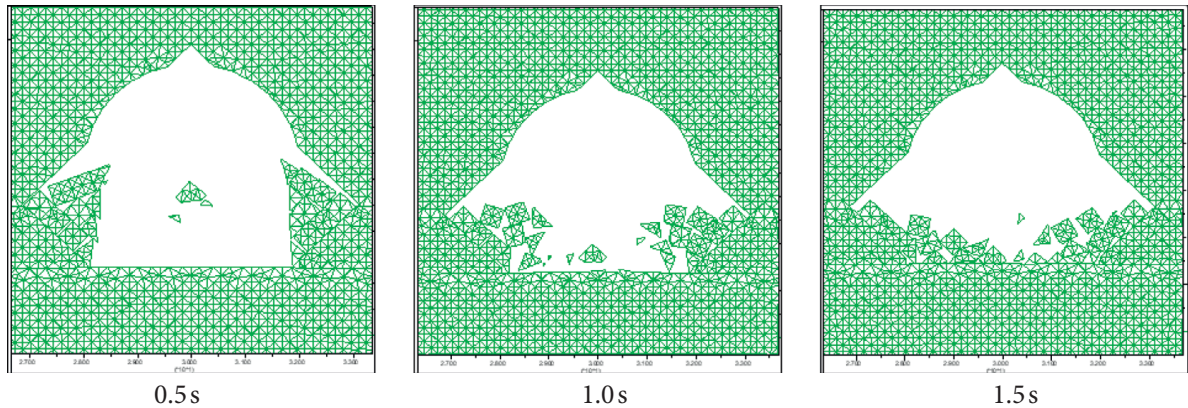

Figure 10: Roadway failure process under a $10 \mathrm{~m}$ thick roof.

the damage to the roadway. The displacements at monitoring points 3 and 4 are shown in Figure 12.

Figure 12 shows that, for monitoring points 3 and 4 on the right, when the direct roof has a thickness of $2 \mathrm{~m}, 6 \mathrm{~m}$, and $10 \mathrm{~m}$, the data pertaining to a $2 \mathrm{~m}$ roof are shown on the left, that on the middle pertains to the $6 \mathrm{~m}$ thick roof, and that on the right pertains to the $10 \mathrm{~m}$ thick roof: other conditions being the same, the roadway first suffers impact damage under the $2 \mathrm{~m}$ thick roof, then under a $6 \mathrm{~m}$ thick roof, and finally under a $10 \mathrm{~m}$ thick roof. The main reason is that the direct top of the coal seam is mudstone, and the rock layer above is fine sandstone. When the top thickness is small, the fine sandstone is thicker; because the mechanical parameters of fine sandstone are larger, the attenuation of vibration is smaller. Therefore, the thinner the roof is, the more the roadway is affected by vibration.

3.4. Influence of Direct Roof Strength on the Roadway. To explore the different effects of the direct roof strength on the vibration wave propagation, the mechanical parameters of the direct roof are changed to be five and 10 times the original values while keeping the thickness of each rock layer constant. The influence of the direct roof strength on the vibration wave propagation characteristics was studied by comparing the failure characteristics of the roadway under different mechanical parameters of the direct roof.

When the direct roof is given its original mechanical parameter, the failure process of the horseshoe roadway is as shown in Figure 13.

When the mechanical parameters of the direct roof are five times their original values, the roadway failure process is demonstrated in Figure 14.

When the mechanical parameters of the direct roof are 10 times their original values, the failure process of the horseshoe roadway is as shown in Figure 15.

According to Figure 15, when the mechanical parameters of the direct roof are different, the failure mode of the whole roadway is similar. The cracks start near the roadway side where the stress is concentrated, about $2 \mathrm{~m}$ from the roadway side boundary. Under dynamic stress, the cracks rapidly expand to 

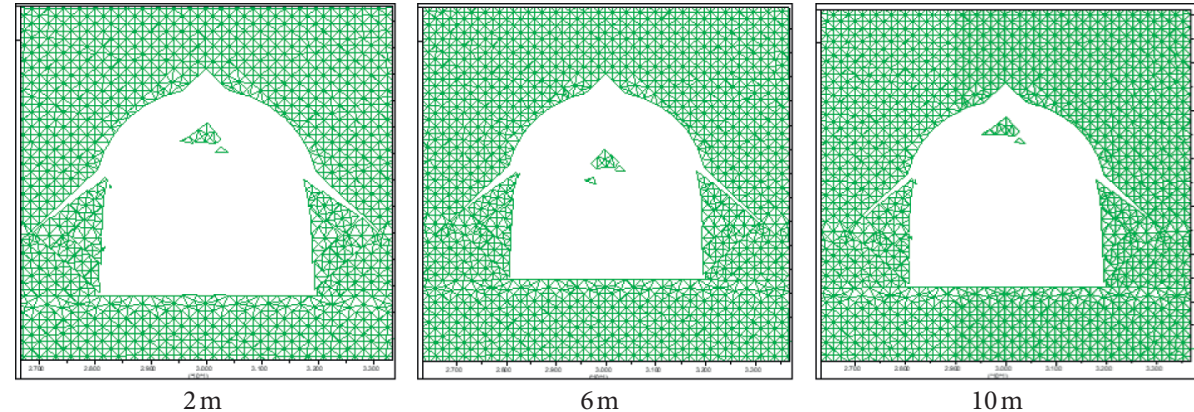

(a)
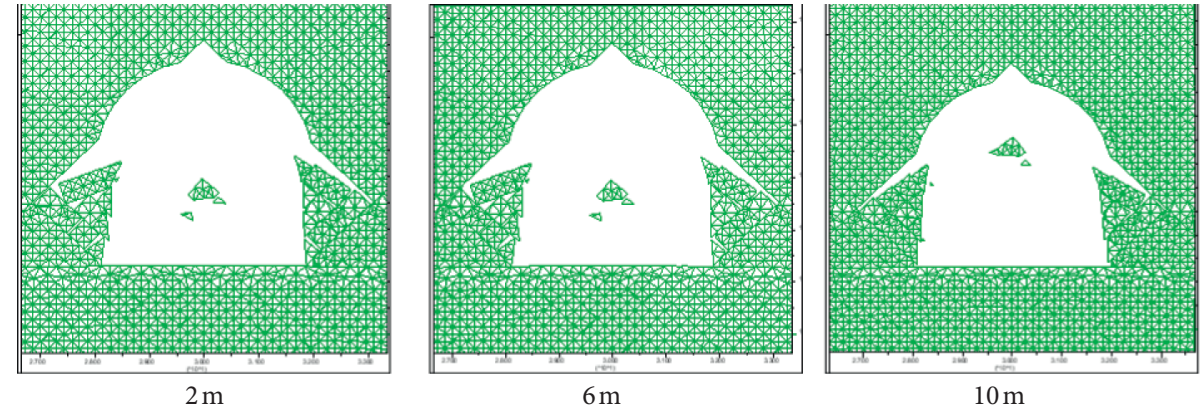

(b)

Figure 11: Comparison of roadway deformations at different times. (a) Comparison of different direct top thickness roadway deformations at $\mathrm{t}=0.3 \mathrm{~s}$. (b) Comparison of different direct top thickness roadway deformations at $\mathrm{t}=0.5 \mathrm{~s}$.

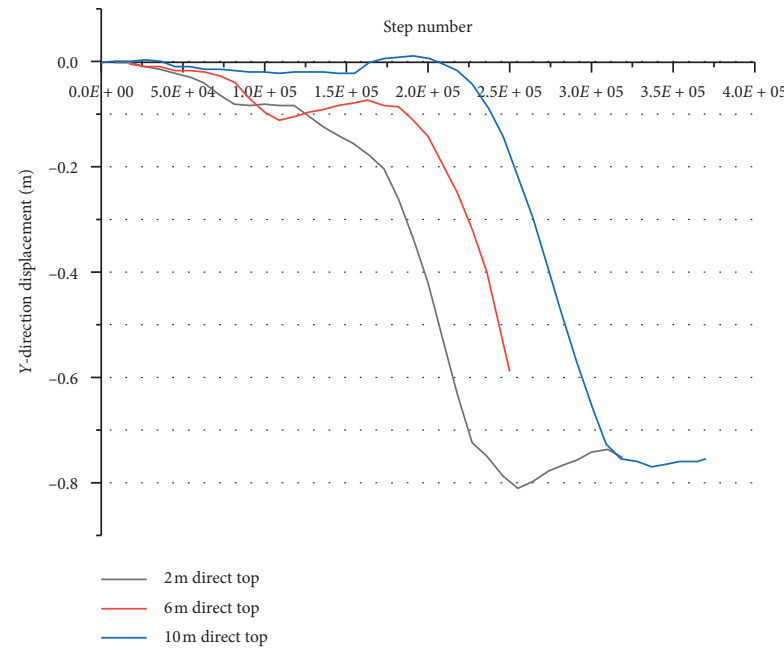

(a)

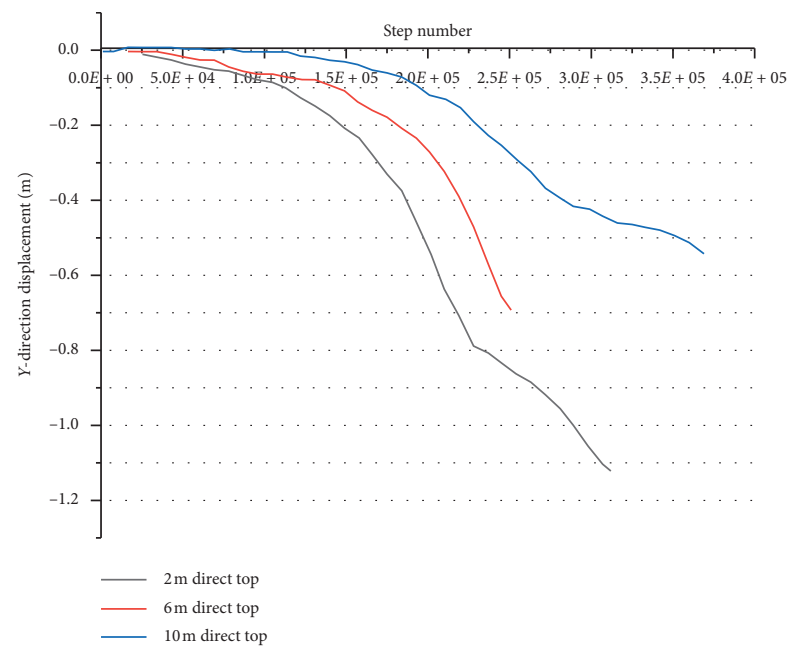

(b)

FIGURE 12: Comparison of $y$-direction deformations. (a) Three-monitoring point displacement curve. (b) Four-monitoring point displacement curve.

the coal and rock mass, forming two cracks, which are symmetrically distributed on the left- and right-hand sides of the roadway and are subject to vibration at the same time. Under the influence of dynamic stress, the coal and rock mass at the top of the roadway fall, and finally the two sides of the rock mass form fragments, which are thrown into the roadway, causing a rock burst.
To explore the influences of mechanical parameters of the direct roof of the roadway, the deformations of roadway at $0.3 \mathrm{~s}$ and $0.5 \mathrm{~s}$ were compared, as illustrated in Figure 16.

Through the comparison of the deformations of the roadway at $0.3 \mathrm{~s}$ and $0.5 \mathrm{~s}$ under roofs of different strengths, it can be seen that the stronger the roof, the greater the deformation of the roadway under dynamic load. The main 

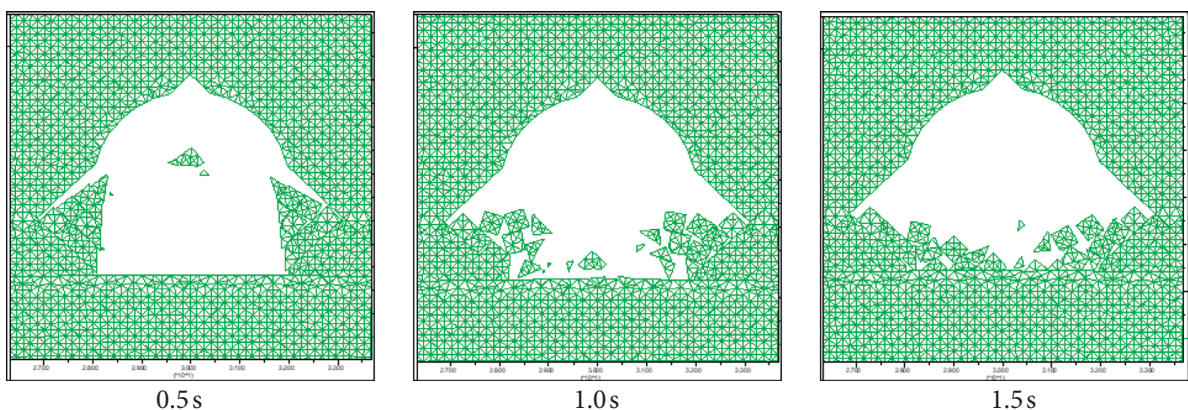

FiguRE 13: Impact ground pressure generation process under original mechanical parameters.
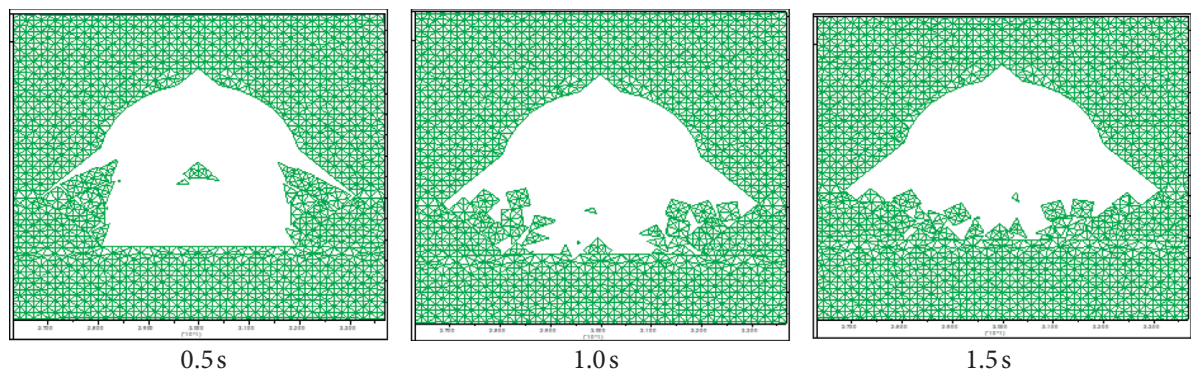

FIgURE 14: Roadway failure process when the mechanical parameters are 5 times their values.

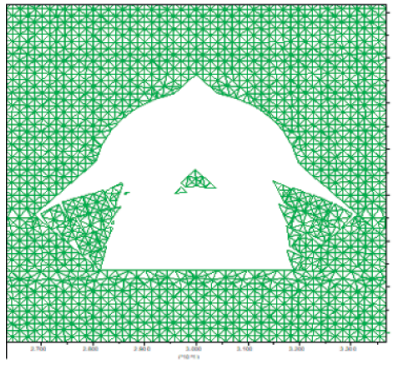

$0.5 \mathrm{~s}$

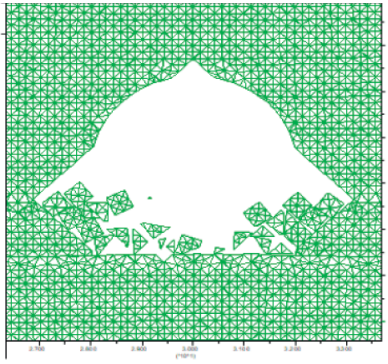

$1.0 \mathrm{~s}$

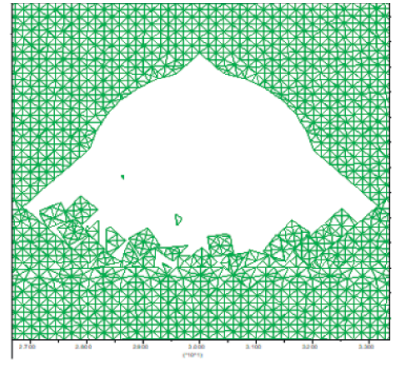

$1.5 \mathrm{~s}$

FIGURE 15: Roadway failure process when the mechanical parameters are 10 times their values.
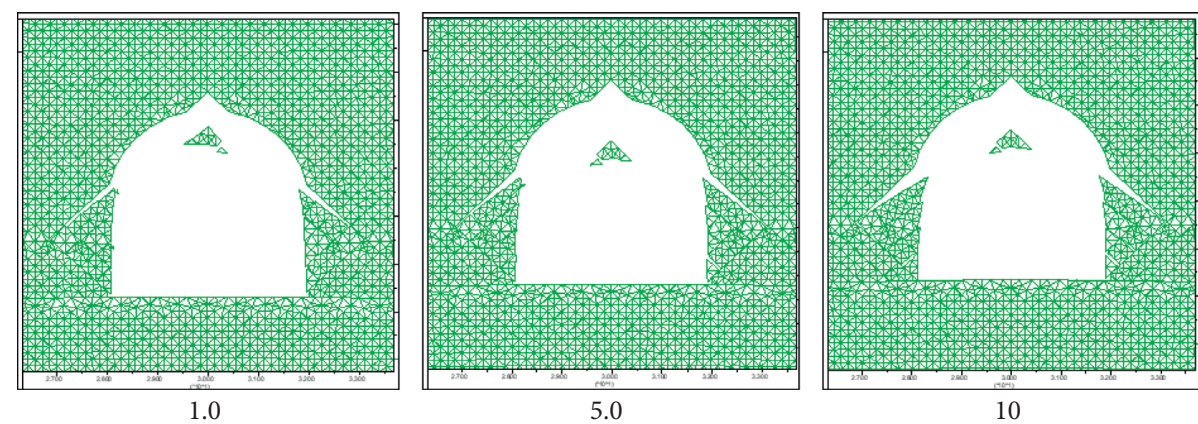

(a)

FIgURE 16: Continued. 


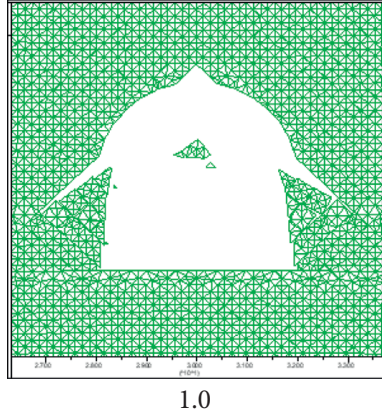

1.0

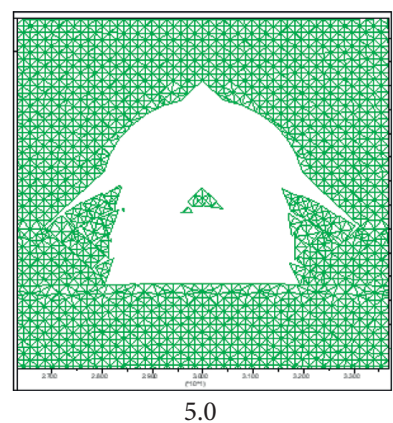

(b)

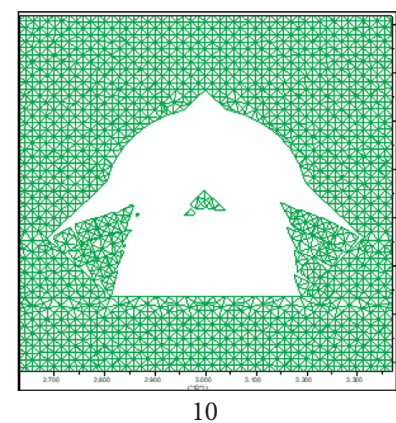

10

Figure 16: Comparison of roadway deformations at different times. (a) Comparison of different roadway deformations at $0.3 \mathrm{~s}$. (b) Comparison of different roadway deformations at $0.5 \mathrm{~s}$.

reason for this is that, when the mechanical parameters of the direct roof are large, firstly, the attenuation effect on the input vibration is reduced, so the stress on the roadway directly affected by the vibration wave is larger; at the same time, when the roof is stronger, more elastic energy is stored, and at failure a rock burst occurs. Through the above analysis, the stronger the roof is, the more the damage is caused under the influence of the same dynamic stress.

\section{Conclusion}

When the rock surrounding the roadway is disturbed by dynamic stress, the crack begins near the side of the roadway where the stress is concentrated: the crack rapidly expands from the starting position to the two sides of coal and rock mass. At the same time, the coal and rock mass in the top area of the roadway fall, and finally the two sides of the coal and rock mass break into blocks and are ejected into the roadway, causing a rock burst.

After a rock-bolt support system had been installed, the same dynamic stress was applied to the roadway, and it underwent little deformation and suffered little damage, which shows that, under certain conditions, bolting can strengthen the surrounding coal and rock mass of the roadway and improve its stability and seismic capacity.

By simulating the strength and thickness of the direct roof, it is found that the thinner the roof, the greater the effect of the dynamic stress on the roadway. Under the action of the same dynamic stress, the stronger the roof is, the more likely a rock burst is to occur and the greater its likely intensity is. The results have been used effectively for the prevention and control of rock bursts in Zhuji mine in Huainan, China.

\section{Data Availability}

Raw data cannot be made available due to data confidentiality.

\section{Conflicts of Interest}

The authors declare that they have no conflicts of interest regarding the publication of this paper.

\section{Acknowledgments}

This research was supported by the National Natural Science Foundation of China (no.5197042023).

\section{References}

[1] Y. S. Pan, Study on the Occurrence and Failure Process of Rock Burst, Tsinghua university, Beijing, China, 1999.

[2] Q. X. Qi, "Theory and practices on stress control of mine pressure bumping," Journal of Mining and Strata Control Engineering, vol. 16, no. 3, pp. 114-118, 2011.

[3] Q. X. Qi, X. L li, and S. K Zhao, "Theory and practices on stress control of mine pressure bumping," Coal Science and Technology, vol. 41, no. 6, pp. 1-5, 2013.

[4] M. T. Zhang, "Forecast and prevention of rockburst in China," Journal of Liaoning Technical University (Natural Science), vol. 20, no. 4, pp. 434-435, 2001.

[5] Y. S. Pan, Z. H. li, and M. T. Zhang, "Distribution, type, mechanism and prevention of rock bursts in China," Chinese Journal of Rock Mechanics and Engineering, vol. 22, no. 11, pp. 1844-1851, 2003.

[6] Y. Yu, X.T. Feng, and B. R. Chen, "Analysis of energy fractal and microseismic information characteristics about immediate rock bursts in deep tunnels with different excavation methods," Rock and Soil Mechanics, vol. 34, no. 9, pp. 2622-2628, 2013.

[7] Y. S. Pan, Y. H. Xiao, and Z. H. li, "Study of tunnel support theory of rock burst in coal mine and its application," Journal of China Coal Society, vol. 39, no. 2, pp. 222-228, 2014.

[8] C. Zhang, S. Tu, and Y. Zhao, "Compaction characteristics of the caving zone in a longwall goaf: a review," Environmental Earth Sciences, vol. 78, no. 1, pp. 27-21, 2019.

[9] F. T. Wang, C. Zhang, S. F. Wei, X. G. Zhang, and S. H. Guo, "Whole section anchor-grouting reinforcement technology and its application in underground roadways with loose and fractured surrounding rock," Tunnelling and Underground Space Technology, vol. 51, pp. 133-143, 2016.

[10] R. N. Singh, I. Porter, and J. Hematian, "Finite element analysis of three-way roadway junctions in longwall mining," International Journal of Coal Geology, vol. 45, no. 2-3, pp. 115-125, 2001.

[11] H. P. Kang, J. Lin, and M. J. Fan, "Investigation on support pattern of a coal mine roadway within soft rocks - a case study," International Journal of Coal Geology, vol. 140, pp. 31-40, 2015. 
[12] Q.-S. Bai, S.-H. Tu, C. Zhang, and D. Zhu, "Discrete element modeling of progressive failure in a wide coal roadway from water-rich roofs," International Journal of Coal Geology, vol. 167, pp. 215-229, 2016.

[13] Q. Bai, S. Tu, F. Wang, and C. Zhang, "Field and numerical investigations of gateroad system failure induced by hard roofs in a longwall top coal caving face," International Journal of Coal Geology, vol. 173, pp. 176-199, 2017.

[14] C. A. Tang, "Numerical simulation of ae in rock failure," Chinese Journal of Rock Mechanics and Engineering, vol. 16, no. 4, pp. 368-374, 1997.

[15] C. A. Tan, H. Liu, P. K. Le, Y. Tsui, and L. G. Tham, "Numerical studies of the influence ofmicrostructucture on failure in uniaxial compression-part 1:effect of heterogeneity," Internationnal Journal of Rock Mechanics and Mining Sciences, vol. 37, no. 4, pp. 555-569, 2000.

[16] H. Y. Liu, S. Q. Kou, P.-A Lindqvist, and C. A. Tang, "Numerical simulation of the rock fragmentation process induced by indenters," International Journal of Rock Mechanics and Mining Sciences, vol. 39, no. 2, pp. 491-505, 2002.

[17] F. X. Jiang, S. H. Yang, and Y. H. Cheng, "A study on microseismic monitoring of rock burst in coal mine," Chinese Journal of Geophysics, vol. 49, no. 5, pp. 1511-1516, 2006.

[18] M. C. He, J. Wang, and X. M Sun, "Mechanics characteristics and applications of prevention and control rock bursts of the negative Poisson's ratio effect anchor," Journal of China Coal Society, vol. 39, no. 2, pp. 214-221, 2014.

[19] P. B. Li, Y. Song, and X. G. Han, "Study on occurrence mechanism of rock burst based on dynamic dilatancy of surrounding rock coal," Science and Technology, vol. 46, no. 11, pp. 30-35, 2018.

[20] G. Y. Yang, F. X. Jiang, X. C. Qu, L. Li, Q. D. Wei, and N. L. Li, "Comprehensive monitoring and early warning technology for rock burst of tunneling face with thick coal seams," Chinese Journal of Geotechnical Engineering, vol. 41, no. 10, pp. 1949-1958, 2019.

[21] F. Wang, "Influence of top slate layer on rock burst in deep and large mining face," Shandong Coal Science and Technology, vol. 12, pp. 186-193, 2018.

[22] L. P. Li, W. J Li, and Y. S. Pan, "Influence of impact disturbance on anomalously low friction rock bursts," Chinese Journal of Rock Mechanics and Engineering, vol. 38, no. 1, pp. 111-120, 2019.

[23] H. T. Li, J. Liu, and S. K. Zhao, "Experimental study on the development mechanism of coal bump considering the clamping effect of roof and floor," Journal of China Coal Society, vol. 43, no. 11, pp. 2951-2958, 2018.

[24] A. W. Wang, S. G. Gao, L. P. Dai, Y. S. Pan, J. Z. Zhang, and J. Q. Chen, "Static and dynamic performance of rebar bolts and its adaptability under impact loading," Journal of China Coal Society, vol. 43, no. 11, pp. 2999-3006, 2018.

[25] Y. L. Tan, M. Zhang, Q. Xu, W. Y. Guo, F. H. Yu, and S. T. Gu, "Study on occurrence mechanism and monitoring and early warning of rock burst caused by hard roof," Coal Science and Technology, vol. 47, no. 1, pp. 166-172, 2019.

[26] X. Y. Li and X. F. Zhang, "Accident cause analysis and prevention measures of typical deep mine heavy pressure bump," Coal Science and Technology, vol. 31, no. 2, pp. 15-17, 2003.

[27] H. Lan, Q. X. Qi, and J. F. Pan, "Analysis on features as well as prevention and control technology of mine strata pressure bumping in China," Coal Science and Technology, vol. 39, no. 1, pp. 11-15, 2011.
[28] Y. D. Jiang, Y. S. Pan, and F. X. Jiang, "State of the art review on mechanism and prevention of coal bumps in China," Journal of China Coal Society, vol. 39, no. 2, pp. 205-213, 2014.

[29] Y. D. Jiang and Y. X. Zhao, "State of the art: investigation on mechanism, forecast and control of coal bumps in China," Chinese Journal of Rock Mechanics and Engineering, vol. 34, no. 11, pp. 2188-2204, 2015.

[30] L. Y. Zhu, Y. S. Pan, and Z. H. Li, "Mechanisms of rock burst and outburst compound disaster in deep mine," Journal of China Coal Society, vol. 43, no. 11, pp. 3042-3050, 2018. 